\title{
Research on Network Aided Training Practice of Electrical and Electronic Engineering
}

\author{
Qin $\mathrm{Xu}^{1, \mathrm{a}}$ and Ningli Liang ${ }^{1, \mathrm{~b}}$ \\ ${ }^{1}$ Jiujiang University, Jiangxi China \\ axuqin918020416@sina.com, 'biangnl@126.com
}

Keywords: Network aided experiment; Electrical and electronic training; Independent design; Innovative experiment; Handling capability

\begin{abstract}
For the disadvantages of traditional mode of the electrical and electronic engineering experiment, the teachers use the scientific tools to improve the quality of the training. Each learner of the electrical and electronic training need analyze and solve the problems with the specialty ability. So the teachers work toward the establishment of network aided experimental training to provide convenient ways for improving students' practical ability. According to practice of network aided experimental training of electrical and electronic, the network experimental platform can effectively provide help for the independent design and the new-style experiments have the prolongation effect on the innovation ability. For the innovative experiment, the center quality of the handling capability can be improved. The network aided training practice is proving that it is important to establish confidence in the quality improvement and it is worth for popularizing and improving.
\end{abstract}

\section{Introduction}

With China's rapid economic development, the community's ability to practice the university graduates have higher requirements. The influence of the traditional education mode, the graduates have theoretical knowledge but lack practical ability. The experiment is an indispensable teaching link in electronic engineering, and it is an important part of the teaching of the basic course of electronics. The electrical experiment can train students' hands-on ability and help to study the basic theory of knowledge playing an important role. The network experimental teaching should be assisted with electrical and electronic training, which is an innovative training mode is to cultivate the electrical and electronic professional students to apply the knowledge and improve the ability of operation.

\section{Problems Existing in the Traditional Electrical and Electronic Experiment Training}

The experimental training in general requirements to complete the experiment within the stipulated time, most students are in accordance with the materials on the operation process, control circuit connection, simple measurement can be completed in accordance with the experimental content, the book summarizes the theoretical knowledge, complete experimental projects assigned by the teacher finally.

Such experimental teaching is able to exercise the ability of students to operate, but a lot of students' thinking and exploring ability, so the electrical and electronic experiment teaching needs further improvement.

Process of Experimental Training. Students do the experimental operation according to the professional book, in that process they are lack of thinking about the experimental purpose. The book of knowledge summary, students can learn without hands-on experiments, resulting in students' negative psychology experiment, this teaching mode does not require students to think independently and design experiment, the experiment teaching has lost significance. Students' understanding of the purpose of the experiment is limited to the surface, the problem will be excluded from the experiment. This experimental teaching model allows students to analyze the problem is not the ability to exercise, to solve the problem is not the ability to show. For the process of experimental teaching is simply to complete the experiment, it is difficult to really stimulate students' interest [1]. 
The Simple Experiment Content. The fundamental task of experiment teaching is to cultivate students' solid theoretical knowledge, in the experiment through the flexible use of theoretical knowledge to demonstrate, through their own objective experimental procedure and experimental design verified the results. In the experiment, the problem is to encourage students to use the knowledge to analyze and solve, to stimulate students' innovative ability. In the traditional education is restricted by various reasons, most of the classroom experiment is through the theoretical support of teaching. Because of the particularity of electrician and electronics, it is difficult for students to combine the knowledge with the real life, and the simple experiment content leads to the unity of the theory and practice of the students.

\section{Implementation of the Electrical and Electronic Experiment Network Auxiliary Training}

Along with our country enters the network information age, through the network auxiliary teaching method can effectively improve the student study the consciousness and the validity. To solve the problems existing in traditional experimental teaching by means of electrical and electronic experiment with network assisted teaching. According to the teaching reform at home and abroad, it is the core of the current teaching to use the network characteristics.

The Implementation of Network Assisted Instruction in Basic Experiment. According to professional operation steps in the teaching material, the teachers arrange to complete the experiment project. Most students are carried out in accordance with the book operation process, through the operation to complete the experiment content, experiment results are obtained. The experiment teaching although exercise the students' operating ability, but also greatly limits the students thinking and exploring space. This experimental teaching mode impacts the students ability to analyze problems and to solve the problem. Just because the teaching task and routing of the experimental teaching, it is difficult to really stimulate students interest in learning.

In the experimental network platform, according to the professional direction of classification, summary of all students will do the experimental project, for the electrical and electronic professional students can be divided into comprehensive and confirmatory experiment. Network experimental teaching can provide students with a number of experimental tools to solve the reality of the limitations of the experimental apparatus. In the network to carry out the experiment can verify a variety of results, to facilitate students to observe and summarize, to help students understand the experimental use of professional knowledge. Before the operation, students can use the network experimental platform to simulate, consolidate the steps of the experiment, each student can carry out the operation of the network experiment, exercise independent analysis ability.

For example of the circuit principle experiment, students overview the circuit connection theory, but lack the concept of electric power and cannot comprehend the relationship analysis between experimental data and the significance, not the actual content of the application to learn.

With the network aided teaching experiment, students can launch the independent design in the virtual experimental platform. They connect the circuit and choose the experimental equipment such as resistance and power which have different parameter. After repeated attempts, students compare and analysis the experimental operation and results, explore the basic theory involved in the experiment, verify the results of the experiment.

The network assisted teaching experiment can let the students from the choice of experimental equipment to start their Independent Design, through repeated attempts, verification, operation of the comparison, from a fundamental understanding of the experimental purposes, to verify the results of the experiment. Through the network experiment to deepen the understanding of theoretical knowledge, let students use the knowledge in the life of a circuit problem analysis and solving, make theoretical and experimental integration, so as to improve the students' interest in learning.

The Implementation of Network Assisted Instruction in Innovative Experiments. The content of network assistant experiment of no fixed section, can let students can be set according to their own interests, the network experimental teaching is focused on the analysis of importance of experiment, 
cultivate students' autonomous ability of thinking. For example, the school can carry out experimental innovation competition, each student in the network can design their own experiments, try to improve the experimental process, through theoretical knowledge to predict the results of the experiment. Make an appointment in the laboratory on the network, to submit their own experimental content, teachers can through the network for students to design experiments are conducted to validate the analysis, supplement and screening of students' innovative ideas, by cooperation between the teachers and students to improve the network experiment of innovative design, to students in reality for innovative experiment. Using network assisted teaching to improve the quality of experimental teaching, encourage students to innovate, so that students actively participate in the professional field of study, in order to adapt to the social requirements of the talent to lay the foundation.

\section{Effect of Electrical and Electronic Experimental Network Assisted Training}

Network aided experimental focus on basic knowledge, strengthen the engineering concept and engineering practice method, according to the basic principle of setting the basic experiment content, help students grasp the important knowledge solutions of the curriculum, and in the experimental practice in the course of scientific research achievements into teaching practice, lay the foundation for further study [2]. The curriculum reform from the perspective of application system, guide the students to think actively, let students complete the key circuit design and implementation, and actively study the various problems of electrical engineering, to guide students to carry out exploratory learning, teaching reform.

For the network assisted electrical and electronic teaching, we can be abstract knowledge specific, through the network experimental extension, let students apply their knowledge to the reality, to help students understand the specific practical electrical and electronic professional. Network experimental teaching can provide more comprehensive information and experimental resources for students, guide the students' interest in learning, cultivate students' ability of rational use of knowledge, inspire innovative thinking ability, learning interest through the mobilization, so that students can actively participate in classroom learning, in-depth system of professional knowledge. Because the electrical and electronic professional needs of students with hands-on ability, so the network experimental teaching can play a huge role in cultivating students' thinking, innovation and practical ability, to enable students to meet the social needs of professional talents of electrical and electronic.

\section{Conclusion}

Network aided experiment training can not only provide students with free space, but also can promote students' learning enthusiasm, help students to consolidate knowledge and cultivate students' engineering concepts in the field of electrical and electronic engineering. In view of the disadvantages of the traditional experimental teaching mode, make full use of scientific tools to improve, establish the network aided experimental training, in order to improve students' practical ability to provide convenient ways. Electrical and electronic professional students hands-on ability and ability to analyze and solve the problems through the network training effectively, encourage students to independent innovation, to improve the quality of students as the center, the establishment of student confidence in the face of social competence. According to the practice of network assisted teaching of electrical and electronic experiments, it is proved that the network experimental platform can provide help for students' learning, and it is worth for popularizing and improving in the training. 


\section{Acknowledgement}

Thanks for the support project: the Science and Technology Support Program of Jiangxi Province (20151BBF60035), the Education Department of Jiangxi Province (JXJG141712) and the Education Planning Project of Jiangxi Province(16YB146).

\section{References}

[1] Liu Qi-long, Based On the Training of Students' Interest in Learning the Course of University Physics Teaching Reform, Hunan Agricultural Machinery. Vol. 40(2013)No.1,pp.160-161.

[2] Gao Xiang. Strengthen General Education in the Experimental Teaching. China University Teaching, (2012) No.11, pp.84-86.

[3] Wang Xi-qin, Xu Shu-zheng, DENG Bei-xing, Thinking of Engineering Practice Teaching in Electronic and Information Science, National College Partnership Committee Annual Meeting Proceedings of Electronic Information Science and Engineering Teaching (Dalian, China, 2009), pp.177-181.

[4] Zhang Kai, The Electrotechnics Teaching Reform Research, Hunan Agricultural Machinery. Vol. 40(2014)No.7,pp.142-143.

[5] $\mathrm{Lu} \mathrm{Sa}$, Reform of the Experiment Teaching and Construction of Electrical and Electronic Experimental Center, Experiment Science and Technology. Vol. 12(2014)No.5,pp.157-159.

[6] Huang Hongzhi, Cai Yanrong, Design of the Network-assisted Teaching System in the Instrumental Analysis Experiment, China Modern Educational Equipment. Vol. 137(2012)No.1,pp.5-7.

[7] Hu Min. The Design and Implementation of Electrical and Electronic Laboratory Teaching System Based on SSH(MS.Jilin University,China 2012), p.27.

[8] Wang Yan. Multisim in Electrical and Electronic Teaching Job Application(MS.Shanghai Normal University,China 2011), p.24.

[9] Yan Hao. Research on Web Virtual Instrument Applicated in Experiment Education Based on LabVIEW(MS.Huazhong University of Science and Technology,China 2007), p.44.

[10] Hong Yin-xing. Build First-class Undergraduate Teaching to Ensure that Education Quality Has Improved Steadily. China Higher Education, (2005 )No.1, pp.14-15.

[11] Yu Wen-bo, Design and Application of Electrician Experiment Assisted Teaching Examination System Based on Labview, Journal of Shenyang Institute of Engineering(Social Sciences), Vol. 9(2011)No.1,pp.123-125. 